\title{
Numerical Simulation of the Diffusion of Fissure Slurry at High Temperature
}

\author{
Jiandong Niu, ${ }^{1}$ Yong Sun $\left(\mathbb{D},{ }^{1}\right.$ Jianxin Liu $\triangle{ }^{2}{ }^{2}$ Huimei Li, ${ }^{1}$ Xiaojun Tan, ${ }^{1}$ Ning Han, \\ Bin Wang $\mathbb{D}^{1}{ }^{1}$ and Liangliang Qiu ${ }^{3}$ \\ ${ }^{1}$ School of Civil Engineering, Central South University, Changsha 410000, China \\ ${ }^{2}$ Swan College, Central South University of Forestry and Technology, Changsha 410000, China \\ ${ }^{3}$ Changsha Hengde Geotechnical Engineering Technology Co., Ltd., Changsha 410000, China
}

Correspondence should be addressed to Jianxin Liu; 6996@hdyt.cn

Received 21 December 2021; Revised 27 January 2022; Accepted 10 February 2022; Published 2 March 2022

Academic Editor: Xueming Du

Copyright (C) 2022 Jiandong Niu et al. This is an open access article distributed under the Creative Commons Attribution License, which permits unrestricted use, distribution, and reproduction in any medium, provided the original work is properly cited.

\begin{abstract}
Deep-buried tunnel at high-ground temperature is prone to the sudden surge of water when crossing the water-rich formation, resulting in casualties and economic losses. Slurry injection is a common and effective method of governance for addressing this issue. However, there has been little research into pulping at high-ground temperature, with most of the existing research focusing on room temperature conditions. We studied two kinds of slurry commonly used in grouting, cement slurry and cement-sodium silicate slurry. Indoor testing was used in this paper to clarify the effect of temperature on slurry viscosity, and numerical simulation was used to study slurry diffusion in flat cracks at different temperatures. The results showed that in a hydrostatic environment, the spread rate of slurry was independent of temperature and type of slurry. For the same kind of slurry, the higher the temperature, the greater the maximum slurry pressure. The higher the temperature in a flow environment, the faster the slurry diffusion. As the temperature rised, the grouting pressure required for crack sealing decreased at first then rises. In a flow environment, the sealing effect of cement-sodium silicate slurry was superior to that of cement slurry.
\end{abstract}

\section{Introduction}

With the continuous construction of deep-buried tunnels all over the world, there are more and more high-temperature tunnels. Groundwater is a harmful component for tunnels [1-5], because it will not only reduce the strength of the surrounding rock but also sudden surges of water may happen when the treatment is not at the time [6-9], resulting in casualties and property damage, and the construction progress may be delayed [10-13]. During operation, groundwater infiltration accelerates the rusting of steel bars in the lining and shortens the service life of the equipment [14-17], increasing the difficulty of maintenance. Grouting is now a widely used groundwater treatment method due to its ease of construction, low cost, and good governance effect [18-23]. Cement and cement-sodium silicate slurry is widely used in the pulping project due to a wide range of raw materials and is nontoxic harmless [24-30].
In recent decades, scholars have done a lot of research on slurry. Li et al. [31] proposed an SDS method to consider the space-time evolution characteristics of slurry viscosity, which describes the slurry diffusion and settlement behavior in the dynamic water of cracks, and realizes the visualization of the slurry diffusion process. Considering the effect of shear rate on the Bingham model, Shamu et al. [32] proposed a new design framework to consider the length of slurry propagation. Yan et al. [33] have developed a hybrid formula for a unified pipe network method combined with a zero-thickness interface unit, which can simulate the crack grouting process and capture the expansion behavior of cracks in the grouting process. Liu et al. [34-35] proposed a numerical flow method for simulating the permeation process of crack rock body grout, and it was discovered that increasing the injection pressure can increase the crack aperture and improve slurry injection efficiency, but it destroys the structure of the rock mass and weakens the injection 
effect. Li et al. [36] carried out a closed seepage test on single-cracked chlorite schist and found that although the growth of rock strength after slurry injection was not ideal, the grout was very effective in reducing permeability. Rafi et al. [37] proposed a new method of slurry analysis to estimate the spread distance of the grout and the size of the crack expansion at a certain time by considering the slurry volume, slurry pressure, ground stress, and the sum of fluid rheum characteristics. Zhang et al. [38] proposed two stepby-step calculation methods to describe the grouting process by dividing the circular slurry area into infinitesimal annular elements, corresponding to the injection pressure boundary conditions and the slurry flow boundary conditions, by dividing the circular slurry area into infinitely small ring units. Xiao et al. [39] analyzed the relationship between crack distribution and slurry characteristics based on discontinuous deformation theory and found that the amount of grout consumed by the crack network was subject to the normal distribution. Du et al. [40] conducted a cement slurry diffusion test in zigzag cracks and discovered that the sealing efficiency of the high fractal dimension is greater than that of the low tortuous fractal dimension of the crack near the injection source, whereas the mode away from the grout source is the opposite [40].

However, the research of domestic and foreign scholars mainly focuses on the diffusion law of slurry at room temperature, and there is less research on the process of the transport of slurry in high-temperature environment. Therefore, it is necessary to explore and study the diffusion characteristics of slurry at high temperatures.

Based on the typical water-rich high-ground temperature tunnel site conditions, the high-temperature environment is simulated indoors, and the viscosity of cement and cement-sodium silicate $(\mathrm{C}-\mathrm{S})$ is measured at different temperatures. The relationship between the diffusion law and temperature of the two types of slurry in the environments of dynamic water and hydrostatic water is revealed through numerical simulation.

\section{The Viscosity of the Slurry at Different Temperatures}

In this paper, the viscosities of cement and C-S slurry at $25^{\circ} \mathrm{C}$, $40^{\circ} \mathrm{C}, 60^{\circ} \mathrm{C}$, and $80^{\circ} \mathrm{C}$ were measured in the laboratory to simulate the change of slurry viscosity in high-temperature environment and provide the material basis for numerical simulation.

The viscosity of the slurry was tested by the Chinese SNB-2 microcomputer digital display viscometer. All the required experimental materials were weighed and heated to $25^{\circ} \mathrm{C}, 40^{\circ} \mathrm{C}, 60^{\circ} \mathrm{C}$, and $80^{\circ} \mathrm{C}$, then mixed in the beaker according to the proportion, and stirred evenly. Finally, the beaker was tested for viscosity using the SNB-2 computer digital viscometer. Three groups of repeated experiments were carried out for each slurry under various temperature conditions, and the average value of the three groups of results was taken as the slurry's viscosity value.

Cement slurry uses P.O.42.5 ordinary sodium silicate cement, and water is ordinary tap water. Water-cement ratio is 0.6 , and each sample is mixed with $300 \mathrm{~g}$ cement and
$180 \mathrm{ml}$ water. Viscosity is measured every $10 \mathrm{~min}$, lasting $120 \mathrm{~min}$. Each C-S slurry is composed of $350 \mathrm{ml}$ liquid A and $70 \mathrm{ml}$ liquid B. Among them, cement slurry, which is P.O.42.5 ordinary silicate cement, is a liquid, and the water-cement ratio is 0.6. Liquid B is a solution of 25 Baume degree sodium silicate diluted with 40 Baume degree sodium silicate. Every $2.5 \mathrm{~s}$, the viscosity is measured. The measurement is terminated when the viscosity exceeds $75 \mathrm{~Pa} \cdot \mathrm{s}$. Figures 1 and 2 show the measurements. The viscosity equations of two different slurries at different temperatures obtained by fitting are shown in Table 1 [41].

The viscosity of cement and C-S slurry increases with the increase of temperature and with the increase of hydration time. Because of the long hydration reaction time of cement slurry, the viscosity of slurry increases slowly. For C-S slurry, the viscosity of the slurry increases suddenly after a while, and an increase in temperature reduces the time required for viscosity rise.

\section{Finite Element Model}

3.1. Model Boundary Condition. The diffusion of slurry is simulated by COMSOL Multiphysics. The motion of slurry in the fissure is regarded as a stratosphere, and water and slurry are regarded as two insoluble fluids. The viscosity characteristics of the slurry are measured by experimental data.

The actual rock mass fractures are simplified as the models of single fissure between two parallel plates with constant aperture, and the spatial scale changes of rock mass fractures are ignored to establish the fracture model shown in Figure 3 [42-44]. The crack length is $3 \mathrm{~m}$, the width is $1 \mathrm{~m}$, the opening is $1 \mathrm{~mm}$, the slurry hole diameter is $6 \mathrm{~cm}$, and the center of the slurry hole is $0.5 \mathrm{~m}$ from the upper and lower boundaries and $1 \mathrm{~m}$ from the left boundary. The free triangle mesh is employed, and it is moderately encrypted near the slurry hole. Two lines are set up in the model to detect changes in pressure within the model, and the line arrangement is shown in Figure 4. The upper and lower boundary of the model is impermeable, and the slurry hole adopts the fixed flow rate boundary, which equates the slurry process to the slurry velocity by the slurry hole wall method. Take the water pressure at the model's outlet as the standard; that is, the pressure at the outlet is zero. The left and right sides are free-flow boundaries in a hydrostatic environment. The right side is still the free-flow boundary in the dynamic flow environment, while the left side is the flow boundary using the fixed head boundary. The working conditions are shown in Table 2.

3.2. Governing Equation of Motion. Regardless of the compression of slurry and water, the Navier-Stokes equation in full form is used to react with the fundamental relationship between fluid flow and force of the continuous equation:

$$
\begin{gathered}
\rho(u \cdot \nabla)=\nabla[-p I+K]+F, \\
\rho \nabla(u)=0, \\
K=\mu\left(\nabla u+(\nabla u)^{\mathrm{T}}\right) .
\end{gathered}
$$




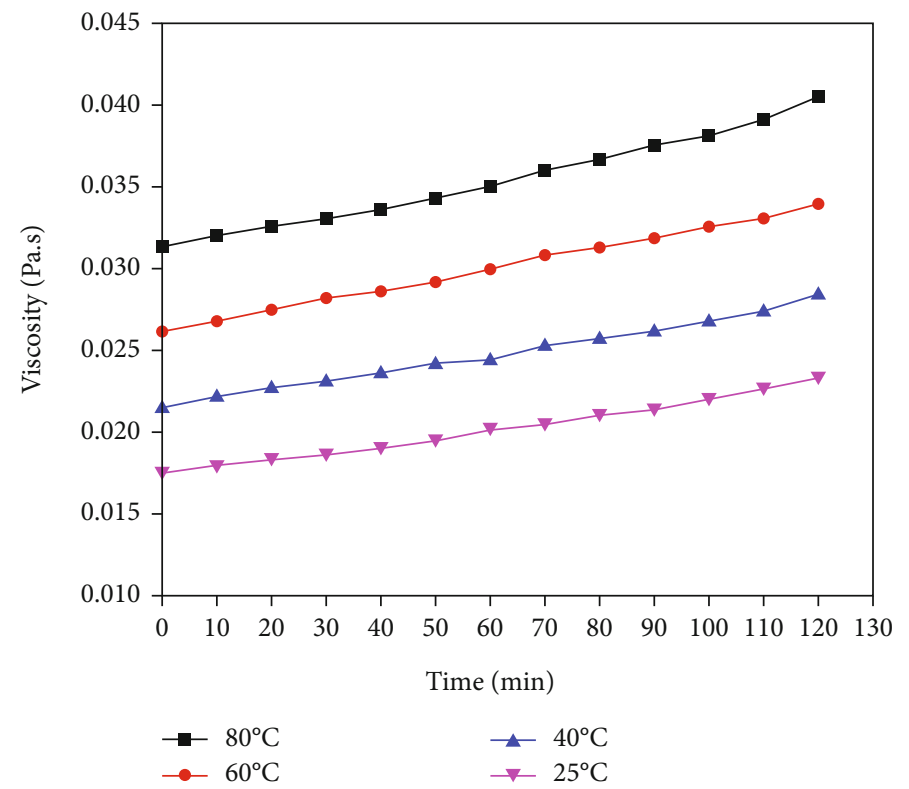

Figure 1: Time-varying viscosity curve of the cement slurry at different temperatures.



Figure 2: Time-varying viscosity curve of the cement-sodium silicate slurry at different temperatures.

In the formula, $\rho$ is the fluid density; $u$ is the velocity field, $p$ is the fluid pressure, $F$ is the volume force on the fluid, and $\mu$ is the power viscosity.

The horizontal set method is adopted to track the movement of slurry water interface, and the governing equation is

$$
\frac{\partial \phi}{\partial t}+u \nabla \phi=\gamma \nabla\left(\epsilon_{l s} \nabla \phi-\phi(1-\phi) \frac{\nabla \phi}{|\nabla \phi|}\right) .
$$

In the formula, $\phi$ is the level set variable, $t$ is the time, $\gamma$
TABLE 1: Temperature and wildlife count in the three areas covered by the study.

\begin{tabular}{lcc}
\hline $\begin{array}{l}\text { Type of } \\
\text { slurry }\end{array}$ & $\begin{array}{c}\text { Temperature } \\
{\left[{ }^{\circ} \mathrm{C}\right]}\end{array}$ & $\begin{array}{c}\text { The time-varying characteristic } \\
\text { equations of viscosity }\end{array}$ \\
\hline \multirow{3}{*}{$\begin{array}{l}\text { Cement } \\
\text { slurry }\end{array}$} & 20 & $\mu=0.01736+4.78571 \times 10^{-5} t$ \\
& 60 & $\mu=0.02144+5.39011 \times 10^{-5} t$ \\
& 80 & $\mu=0.02614+6.45055 \times 10^{-5} t$ \\
& 20 & $\mu=0.03096+7.35165 \times 10^{-5} t$ \\
C-S slurry & 40 & $\mu=2.71354 \times 10^{-11} t^{6.76022}$ \\
& 60 & $\mu=2.18059 \times 10^{-8} t^{5.38292}$ \\
& 80 & $\mu=8.93584 \times 10^{-5} t^{3.50253}$ \\
& & $\mu=3.21232 \times 10^{-4} t^{3.4143}$
\end{tabular}

$\mu$ : viscosity; $t$ : time. For cement, the unit of $t$ is [min]. For C-S, the unit of $t$ is $[\mathrm{s}]$.

is the reinitialization parameters, and $\epsilon_{1 \mathrm{~s}}$ is the control interface thickness parameters.

\section{Law Analysis of the Hydrostatic Environment}

4.1. Diffusion Pattern of the Hydrostatic Environment. Through simulation, it is found that the diffusion shapes of the two grout at different temperatures are almost the same in the hydrostatic environment, and all of them show the morphology as shown in Figure 5, where the red part represents the slurry and the blue part represents the water.

The diffusion speed of the slurry along the four directions is equal, and the diffusion area is circular. The slurry's diffusion is then blocked by the boundary, the spread to the boundary is slowed, and the slurry's diffusion shape changes. 


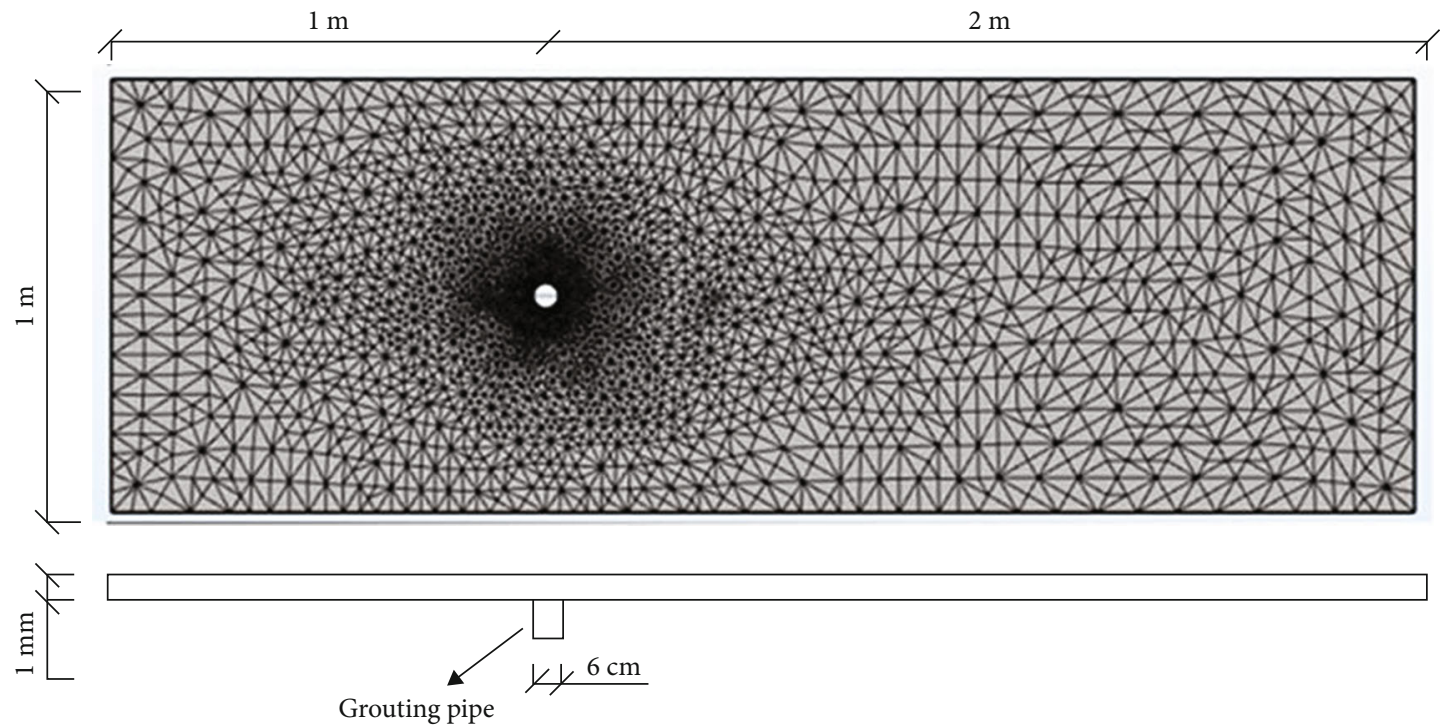

FIGURE 3: Geometric model and mesh division.

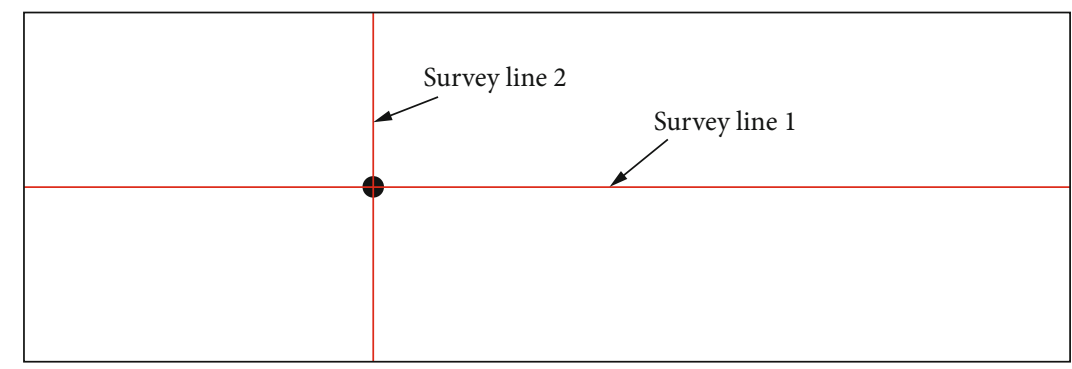

Figure 4: Arrangement of survey line.

TABLE 2: Working conditions.

\begin{tabular}{lccc}
\hline $\begin{array}{l}\text { Type of } \\
\text { grouting slurry }\end{array}$ & $\begin{array}{c}\text { Grouting rate } \\
{[\mathrm{m} / \mathrm{s}]}\end{array}$ & $\begin{array}{c}\text { Inlet pressure } \\
{[\mathrm{kPa}]}\end{array}$ & Temperature $\left[{ }^{\circ} \mathrm{C}\right]$ \\
\hline $\begin{array}{l}\text { Ordinary } \\
\text { cement }\end{array}$ & 0.20 & 0 & $25,40,60,80$ \\
$\begin{array}{l}\text { C-S } \\
\begin{array}{l}\text { Ordinary } \\
\text { cement }\end{array}\end{array}$ & 0.20 & 0 & $25,40,60,80$ \\
C-S & 0.50 & 10 & $25,40,60,80$ \\
\hline
\end{tabular}

Furthermore, the figure clearly shows that the slurry's diffusion rate is high at first, but as the pulping progresses, the diffusion radius increases, and the diffusion rate gradually decreases, and at $25 \mathrm{~s}$, the slurry diffuses to the crack boundary and the slurry sealing is completed. It can be considered that the diffusion of grout in a hydrostatic environment is independent of temperature and type of grouting slurry.

\subsection{Pressure Field Variation}

4.2.1. Pressure Contour. Similar to the diffusion trajectory, the shape of pressure isolines at different grout types and temperatures is the same, and all of them show the morphol- ogy as shown in Figure 6, which is circular near the slurry hole and is more densely distributed, while the pressure contours away from the position of the slurry hole are sparse, indicating that the pressure decreases rapidly in the fluid. The pressure contours begin to appear further away from the slurry holes as the pulping progress, indicating that the pressure's influence range is expanding, and this part of the pressure contours is not a closed curve due to the obstruction of the boundary.

4.2.2. Grouting Time Distribution. However, the numerical value of the pressure contour is different at different temperatures and slurry types. The slurry pressure rises as the ground temperature rises. Figure 7 shows the relationship between injection pressure and time by monitoring the position pressure of the injection hole. It can be seen that for cement slurry, the slurry pressure increases linearly over time, and for every $20^{\circ} \mathrm{C}$ increase in temperature, the slurry pressure increases by an average of $10 \mathrm{~Pa}$. For C-S slurry, when the temperature is below $60^{\circ} \mathrm{C}$, the injection pressure also increases linearly over time, but when the temperature reaches $80^{\circ} \mathrm{C}$, the growth rate of the injection pressure increases with the injection time, and the pressure increases with time. For the same type of slurry, the higher the 

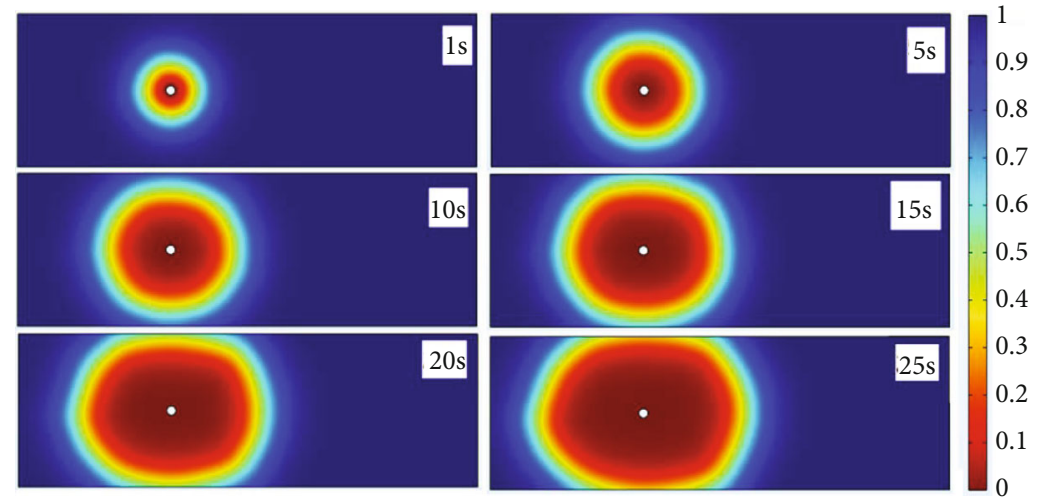

Figure 5: Static water diffusion morphology.

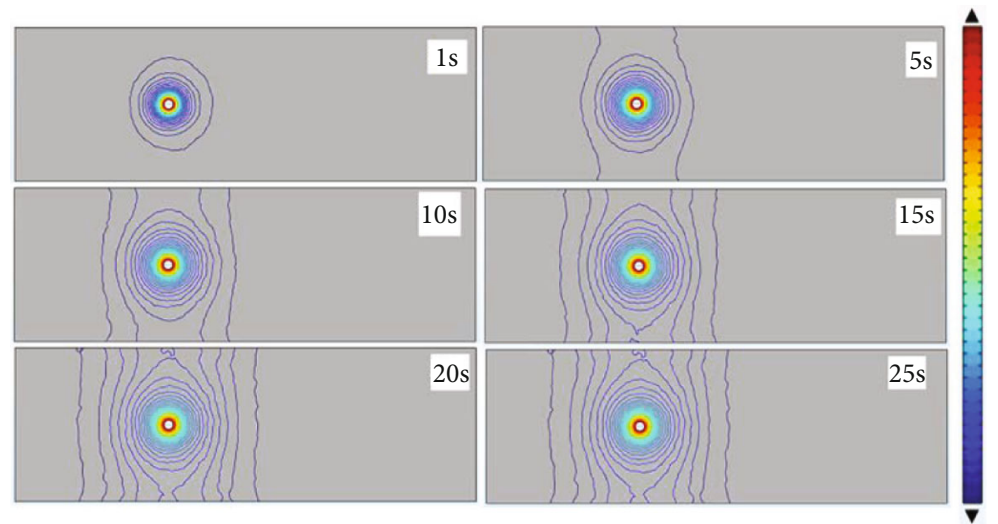

Figure 6: Pressure contour.

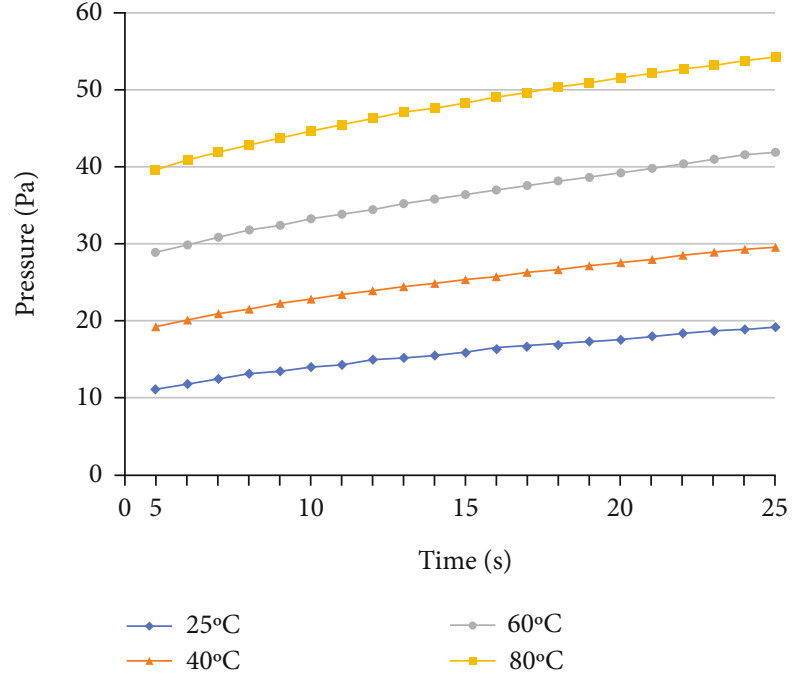

(a) Cement

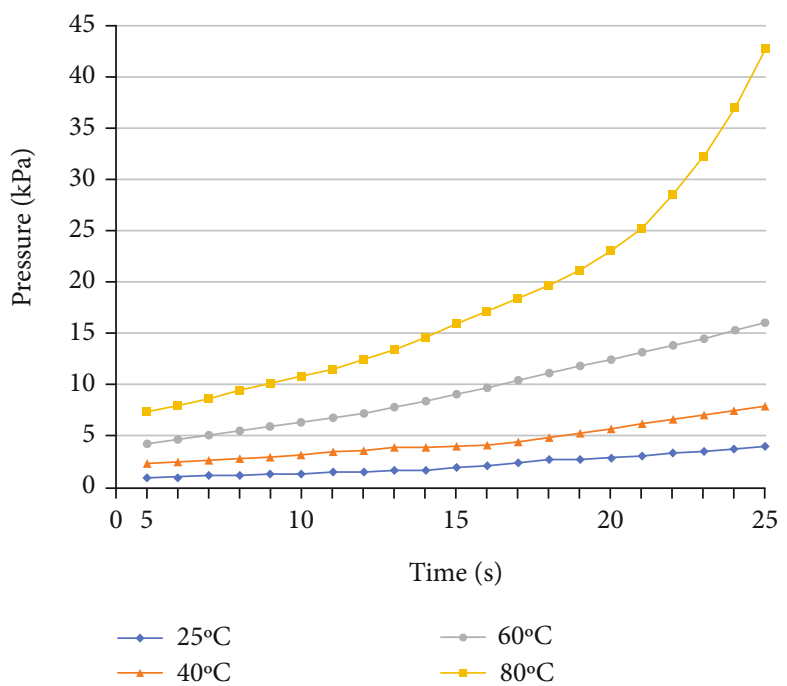

(b) C-S

FIGURE 7: Pressure time variation.

temperature, the higher the viscosity at the same time and the faster the viscosity growth rate, and C-S slurry injection pressure is much higher than cement slurry injection pres- sure, C-S slurry pressure growth rate is much higher than cement growth rate, and C-S slurry pressure is hundreds of times cement pressure. 




Distance from grouting hole $(\mathrm{m})$

\begin{tabular}{|c|c|}
\hline$\multimap \quad 25^{\circ} \mathrm{C}, 5 \mathrm{~s}$ & $-60^{\circ} \mathrm{C}, 5 \mathrm{~s}$ \\
\hline$-25^{\circ} \mathrm{C}, 15 \mathrm{~s}$ & $\longrightarrow 60^{\circ} \mathrm{C}, 15 \mathrm{~s}$ \\
\hline$\triangle \quad 40^{\circ} \mathrm{C}, 5 \mathrm{~s}$ & $-80^{\circ} \mathrm{C}, 5 \mathrm{~s}$ \\
\hline $40^{\circ} \mathrm{C}, 15 \mathrm{~s}$ & $-80^{\circ} \mathrm{C}, 15 \mathrm{~s}$ \\
\hline
\end{tabular}

(a) Cement

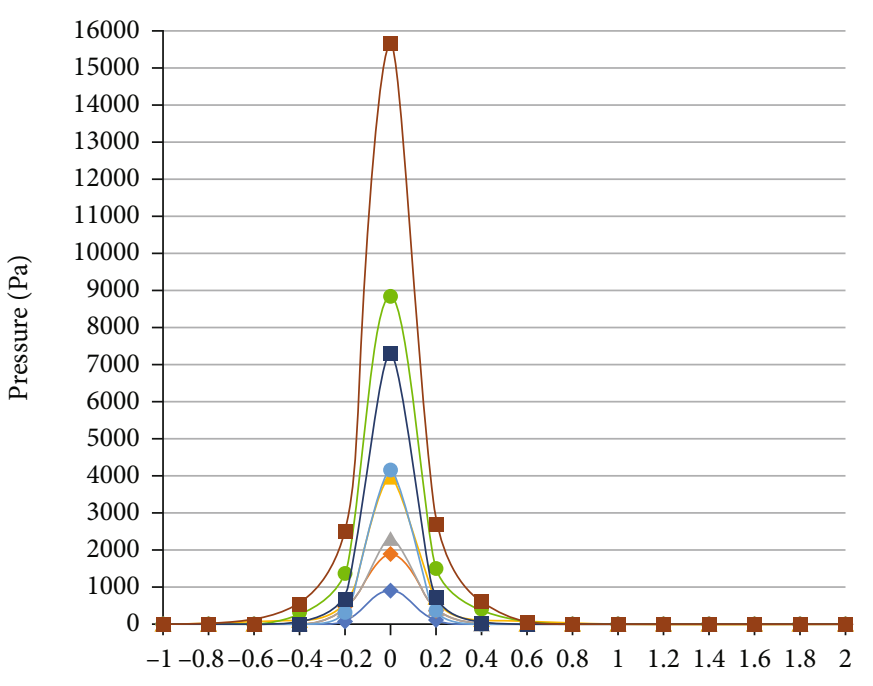

Distance from grouting hole (m)

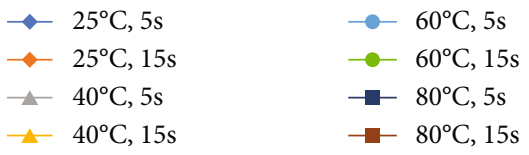

(b) C-S

Figure 8: Pressure distribution on survey line 1.

4.2.3. Pressure Spatial Distribution. With the injection hole as the center, the pressure distribution on line 1 and line 2 can be monitored with the change of slurry type and temperature; as shown in Figures 8 and 9, the distribution of specific pressure size can be obtained. The analysis of these graphs reveals that the injection pressure increases all along the line as the injection process progresses, and that the higher the temperature at the same time, the greater the pressure on the measuring line, and the greatest increase in pressure at the injection hole. In addition, on line 1, the pressure in the fluid gradually approaches $0 \mathrm{~Pa}$, i.e., the outflow boundary pressure, and the later the time, the higher the temperature, the greater the pressure, and the longer it takes to drop to $0 \mathrm{~Pa}$. Because of the boundary blocking, the pressure on line 2 will not be reduced to $0 \mathrm{~Pa}$, and the minimum pressure will increase as injection time and temperature increase. Furthermore, the pressure in the fluid is the symmetrical distribution of the injection hole, and the pressure of C-S slurry at the same position is much greater than the pressure of cement slurry.

Although the size of the pressure in the fluid changes with temperature, time, type of slurry, etc., the law of attenuation has not changed: the attenuation of the injection pressure slows as it moves away from the slurry hole, and the attenuation of the pressure of $0.2 \mathrm{~m}$ in the injection hole is completed $80 \%$ and $90 \%$ in $0.4 \mathrm{~m}$, the higher the temperature, the faster the pressure attenuation speed near the slurry hole, which is also in line with the distribution of the pressure contour, and the pressure attenuation speed on line 2 is lower than the measuring line 1 .

\section{Diffusion Law of the Flow Environment}

5.1. Diffusion Morphology Analysis. Under the condition of flow environment, the diffusion trajectory of grout becomes different due to the scour of water flow.

5.1.1. Cement Slurry. It is a cement slurry because of its small viscosity; so, the ability to resist the flow of water washing is weak. In the process of filling, most of the cement slurry is taken away by the water flow. Furthermore, the diffusion of cement slurry varies greatly in different directions: cement slurry primarily spreads along the water, and diffusion in the reverse water direction is almost nonexistent. The distribution of cement slurry in a wavy shape can be seen near the model's exit. Furthermore, while the viscosity of cement slurry increases slightly with temperature, it is still insufficient to resist the washing of water flow. The change in cement grout diffusion morphology with increasing temperature is not obvious in the simulated period, and all of them show the morphology shown in Figure 10.

5.1.2. C-S Slurry. C-S slurry as a quick condensate, viscosity can be raised in a short period to a value sufficient to resist the flow of water wash and seal the fissure, and the temperature effect is also very obvious. Unlike static water injection slurry, the initial slurry sealing speed is slower in dynamic water due to the strong flushing of water flow, and with the injection of slurry, C-S slurry viscosity increases, the ability to resist water flow is stronger, blocking speed is faster, and the higher the temperature. The time required 


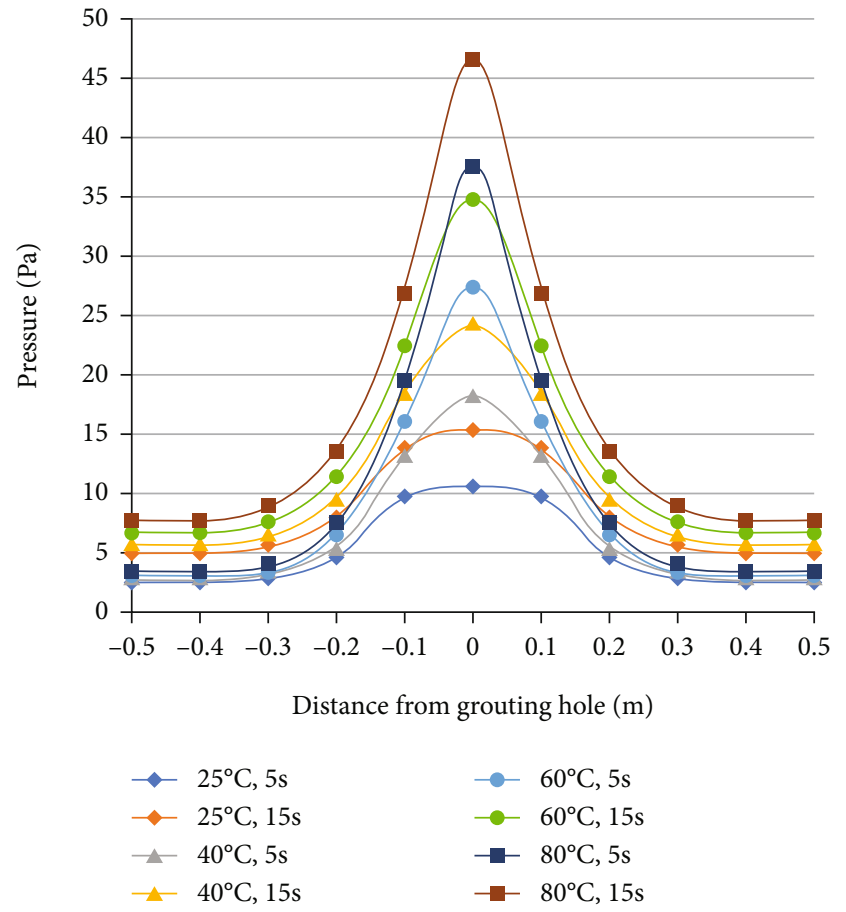

(a) Cement

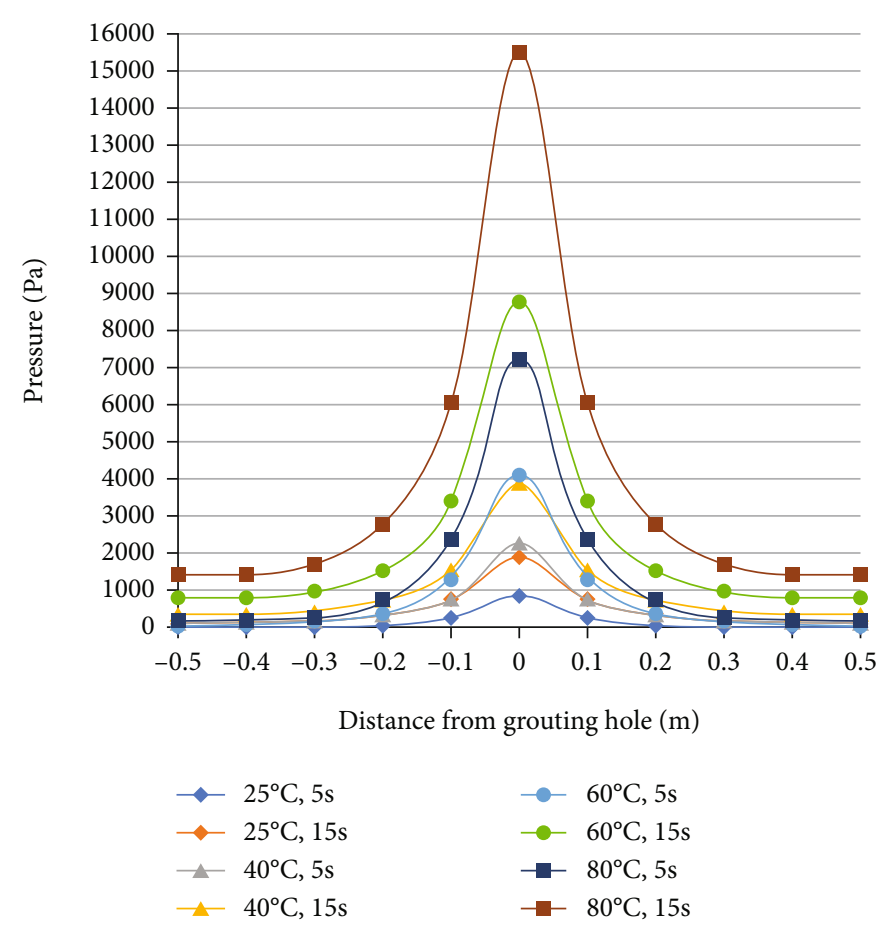

(b) C-S

FIGURE 9: Pressure distribution on survey line 2.
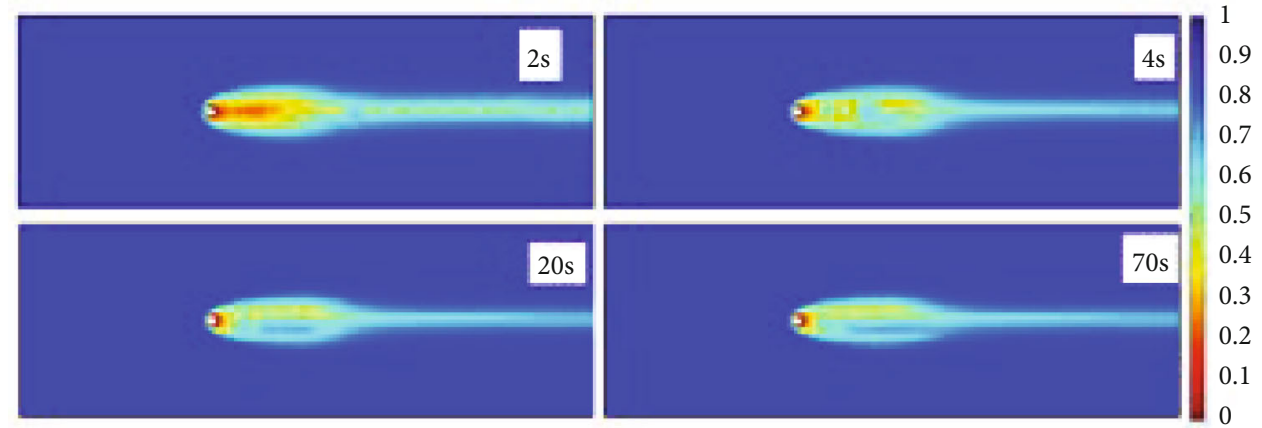

Figure 10: Diffusion morphology of cement.

for blocking is shorter, and the time required for blocking is $75 \mathrm{~s}, 70 \mathrm{~s}, 55 \mathrm{~s}$, and $50 \mathrm{~s}$, respectively, at $25^{\circ} \mathrm{C}, 40^{\circ} \mathrm{C}, 60^{\circ} \mathrm{C}$, and $80^{\circ} \mathrm{C}$. The specific diffusion trajectory of the C-S slurry is shown in Figure 11. It can be seen that the diffusion of C-S slurry is divided into three stages.

In the first stage, due to the low viscosity of C-S slurry, most of the C-S slurry is taken away by water flow, only after the injection hole retains the lower part of C-S slurry reverse water, and the spread of both sides is very small.

In the second stage, with the injection of slurry, C-S slurry viscosity continues to increase, it begins to be able to resist the wash of water flock, C-S slurry gradually spread to both sides and the opposite side of the water, and the reverse water side diffusion rate is slower than on both sides due to the more intense flushing.
In the third stage, due to the spread of C-S slurry to both sides, the fissure is gradually blocked, the water flow speed is slowing down, the flushing effect of the water flow is decreasing, the diffusion speed of the opposite waterside is gradually accelerated, and in the direction of vertical water flow, because the water flow channel becomes narrow, the water flow rate decreases slowly, which leads to the water flow on both sides of the injection hole is still strong, so that the flow rate of C-S slurry in this direction is less than the diffusion speed of C-S slurry in the direction of the reverse water.

As the temperature of water increases, the first two stages of the slurry take up less and less time, and when it reaches $80^{\circ} \mathrm{C}$, the first stage is no longer observed. In addition, the temperature increases. The time required for crack sealing is also decreasing, with temperature increases from 


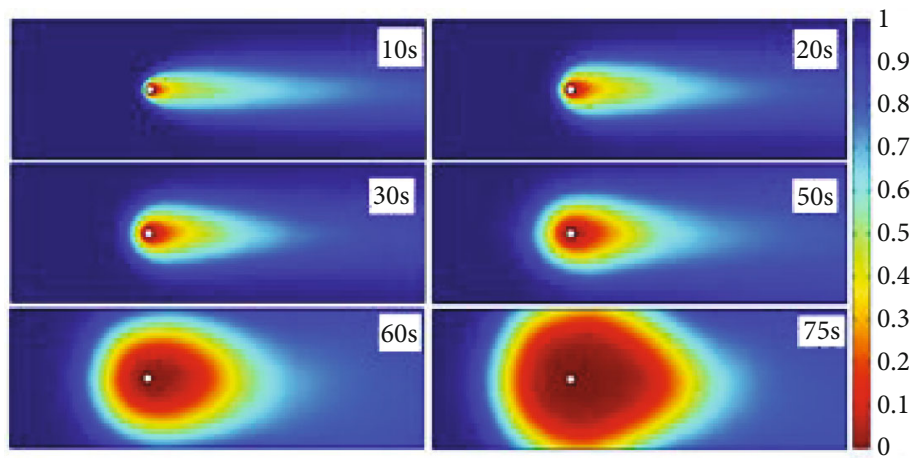

(a) $25^{\circ} \mathrm{C}$

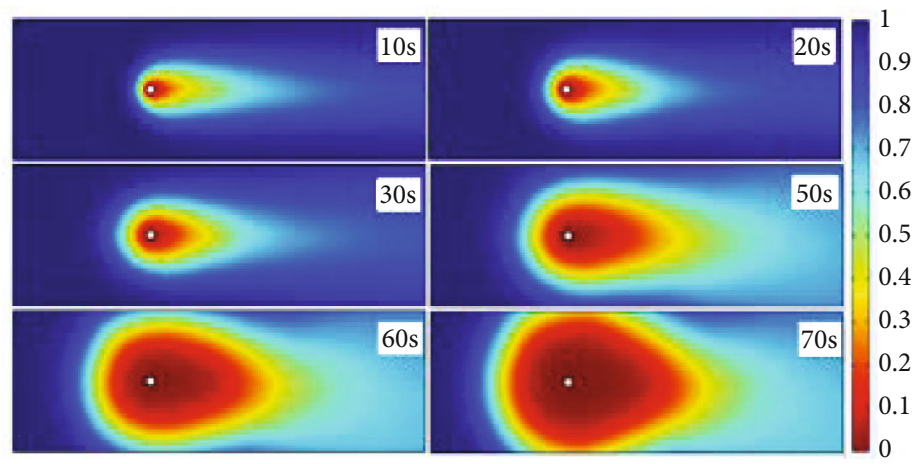

(b) $40^{\circ} \mathrm{C}$

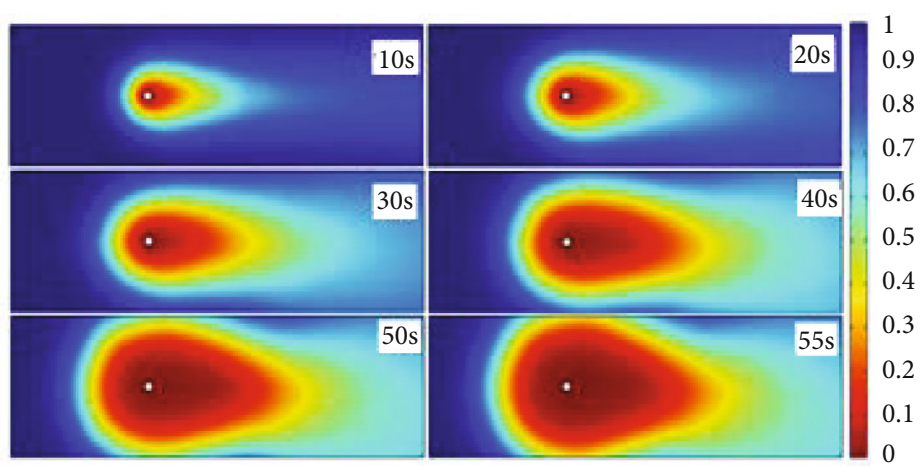

(c) $60^{\circ} \mathrm{C}$

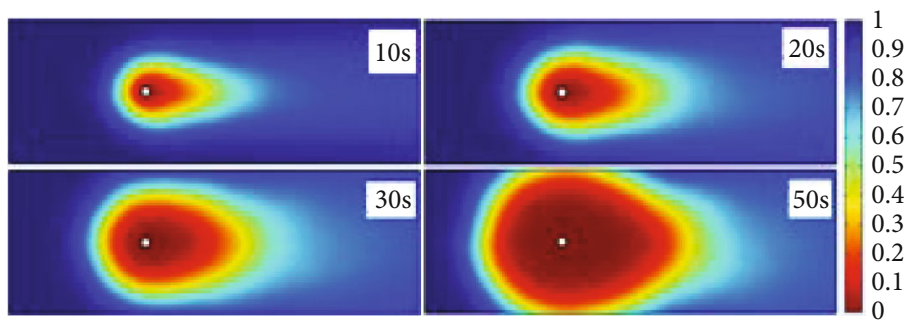

(d) $80^{\circ} \mathrm{C}$

FIGURE 11: Diffusion patterns of C-S grout at different temperatures.

$25^{\circ} \mathrm{C}$ to $40^{\circ} \mathrm{C}$, from $40^{\circ} \mathrm{C}$ to $60^{\circ} \mathrm{C}$ reducing crack sealing time by $5 \mathrm{~s}$, and time to seal from $40^{\circ} \mathrm{C}$ to $60^{\circ} \mathrm{C}$ decreasing by $15 \mathrm{~s}$. The analysis suggests that when the temperature is lower, the viscosity change is relatively small, and the slurry efficiency changes little, whereas when the temperature is higher, the flow rate of the slurry is the dominant factor in the time required for sealing, limiting the further reduction of the blocking time.

In this model, it can be seen that in this model, C-S slurry dynamic water pressure is higher, and the slurry flow rate is lower, but it can complete the sealing of the fissure in a short period, and at the same time, the cement slurry is still 


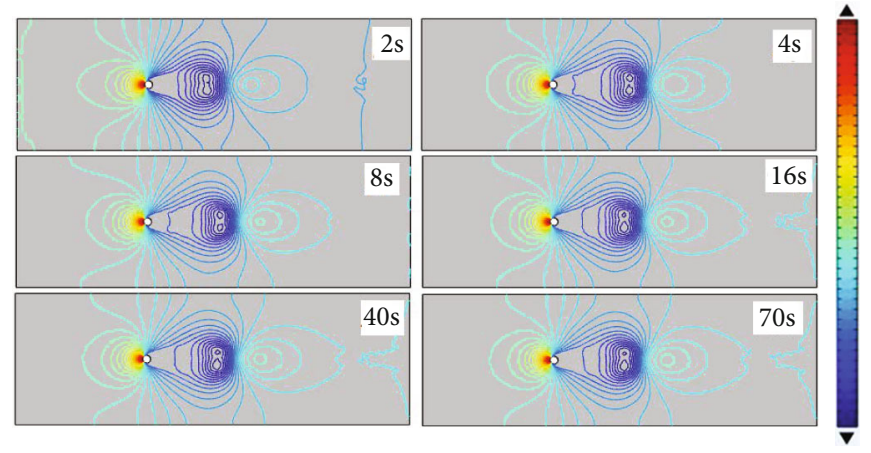

FIGURE 12: Cement slurry pressure contour.

not resistant to flushing and cannot complete the crack sealing work. Therefore, in the dynamic water environment, C-S slurry blocking effect is better than cement slurry.

\subsection{Pressure Field Variation}

\subsubsection{Variation in Cement Slurry Pressure Field}

(1) Pressure Contour. The viscosity of cement changes at different temperatures is small enough in the dynamic water environment to cause the pressure contour to change significantly, the pressure contour distribution at different temperatures is the same, the numerical size difference does not exceed 5\%, and the specific distribution is shown in Figure 12. The pressure distribution around the slurry hole is extremely complex at this point.

It can be seen that the distribution of pressure contours can be divided into three parts: the left side of the slurry hole, the spread of the two sides of the slurry increasing, that is, the head of the "comet," and the spread of the two sides of the slurry suddenly reduced, that is, the tail of the "comet." The pressure value is high on the left side of the injection hole, the pressure contour forms a closed shape through the slurry hole, and the distribution at the injection hole is dense. Because of the winding, the pressure at the head of a comet is minimal or even negative, and the pressure contours are very dense at the comet's head and tail junction. The pressure contours in the tail area are closed ringshaped and sparsely distributed.

(2) Pressure Time Distribution. The distribution of pressure contours can be seen, and the injection hole reverse water measurement pressure is the largest; so, the reaction pressure at this position changes over time, as shown in Figure 13. In the initial stage of slurry injection, the pressure rises rapidly, basically stable after $8 \mathrm{~s}$, the pressure size at different temperatures is the same, and the difference is not more than 5\%; so, the rapid increase of cement slurry pressure is not related to the viscosity change of cement slurry, presumably due to the change of slurry diffusion pattern makes the water's winding movement change, so that the pressure is rising rapidly.

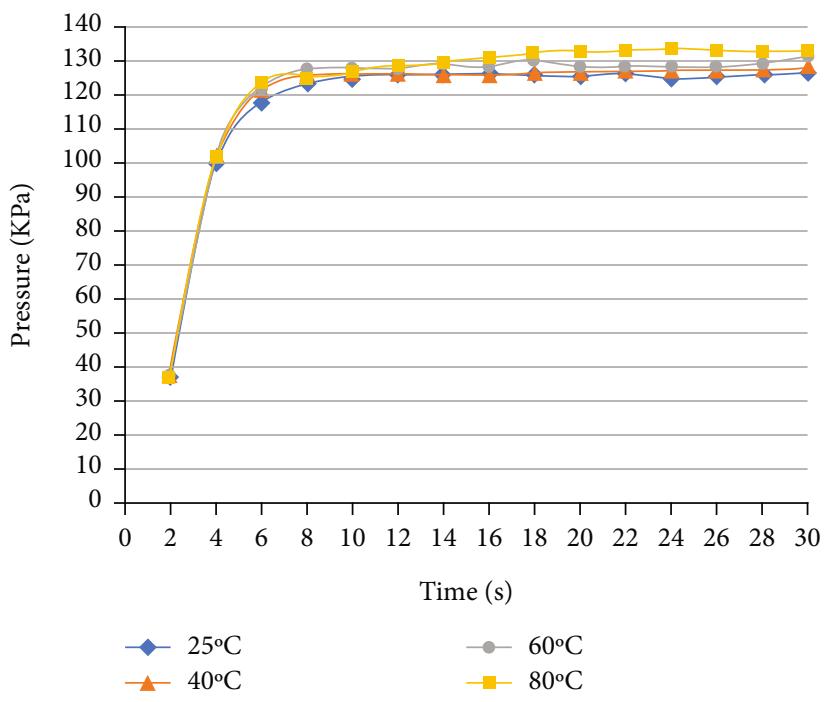

FIGURE 13: Grouting pressure varies with time of cement slurry.

(3) Pressure Spatial Distribution. Monitor the distribution of pressure on line 1 and line 2, as shown in Figure 14. On line 1 , on the reverse waterside, the slurry pressure decays rapidly after moving away from the injection hole, the attenuation of $0.2 \mathrm{~m}$ pressure in the injection hole is $80 \%$, and $90 \%$ is done within $0.4 \mathrm{~m}$. On the water side, a clear negative pressure zone is produced due to the flow of water, the pressure along the direction of the water first drops and then rises, to $0.8 \mathrm{~m}$ rise to the maximum value, and then began to slowly drop to 0 , and the longer the injection time, the larger the negative pressure area and the greater the minimum and maximum pressure. On line 2, the pressure increases from a negative value that increases to a maximum value at $0.1 \mathrm{~m}$ and remains the same, and the value decreases with the injection.

5.2.2. Variation in C-S Slurry Pressure Field. Unlike cement slurry, the change of viscosity of C-S slurry at different temperatures is very significant, which makes the change of pressure at different temperatures obvious.

(1) Pressure Contour. The change of pressure contour in the pulping process is shown in Figure 15 and can be roughly 

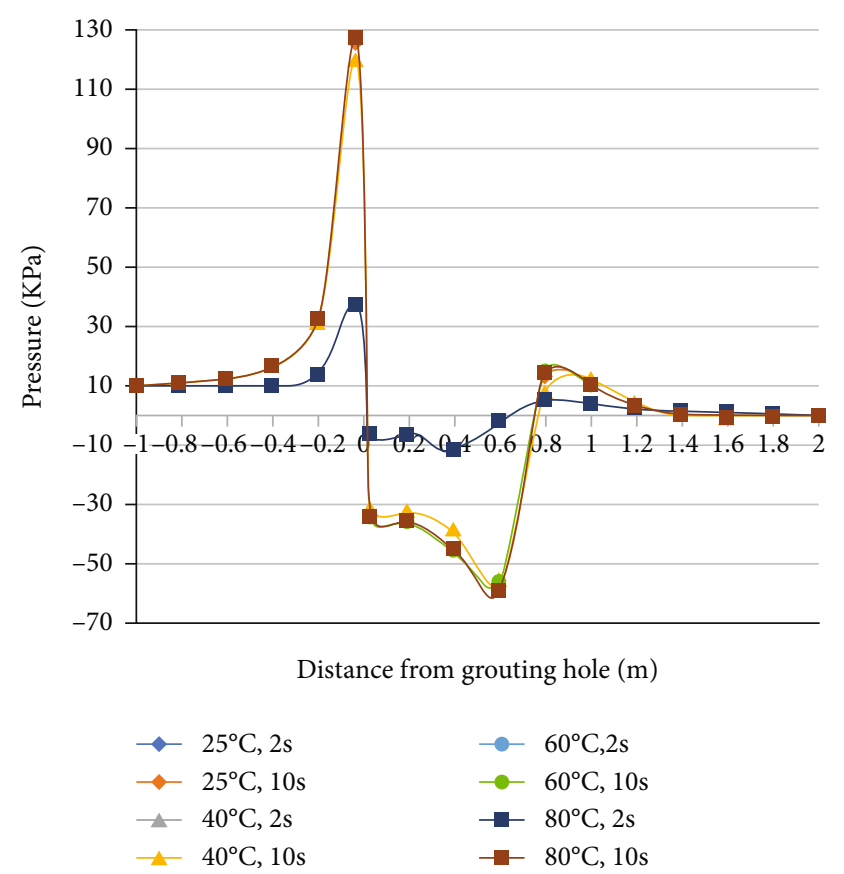

(a) Line1

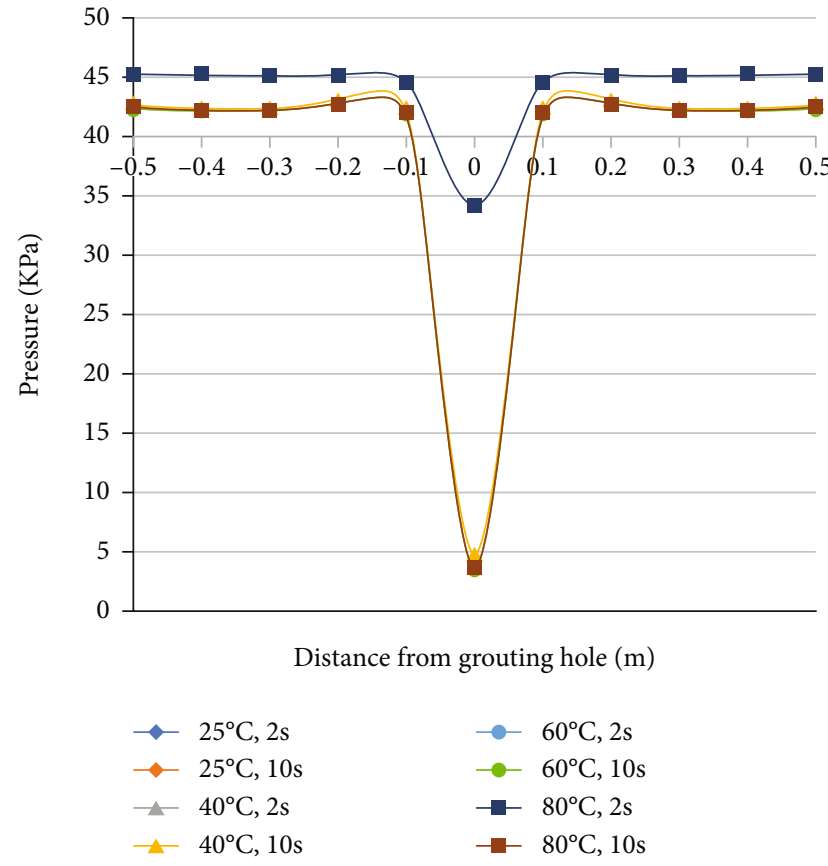

(b) Line2

FIGURE 14: Variation of cement slurry pressure space.

divided into four stages. In the first stage, the pressure contours near the injection hole are all passed through the injection hole, the pressure contours on the inverse water side of the injection hole are elliptical, the pressure contours on both sides are the dividing line of the slurry hole, the pressure contours on the counter water side of the slurry hole are curved in the direction of reverse water, and the pressure contours on the water side of the slurry hole are curved in the direction of the water. The pressure contour is perpendicular to the initial flow rate of the moving water on the down water side away from the injection hole. In the second stage, the pressure contours on the inverse water side of the injection hole gradually extend outwards and change from closed to nonclosed, and the pressure contours become sparse. In the third stage, the nonclosed pressure contours on the inverted water side of the injection holes gradually disappear, and the closed pressure contours that wrap the slurry holes begin to appear near the injection holes, and the closer the injection holes, the denser the pressure contours. In the fourth stage, the vertical pressure contour appears on the inverse water side of the injection hole, and the pressure contour in the model is similar to the shape of the pressure contour in the slurry hole. Furthermore, as the temperature rises, the time required for the first two stages decreases gradually. At $40^{\circ} \mathrm{C}$, the first stage of the pressure contour is difficult to observe, and when the temperature reaches $80^{\circ} \mathrm{C}$, the first and second stages are difficult to observe.

To monitor the pressure on the water side of the slurry hole, Figure 16 is obtained. The analysis found that at the beginning of the injection, the slurry because of the small viscosity of C-S slurry, low diffusion, and the winding effect of the water flow is strong, and the pressure is greater. With the pulping, the C-S slurry spreads further, the winding action is reduced, and the pressure gradually decreases; then, because the viscosity of the slurry is high, it becomes the main factor affecting the pressure size, and the pressure begins to rise as the viscosity increases. When the local temperature is above $40^{\circ} \mathrm{C}$, the viscosity of the slurry is large, the effect of the increase of viscosity on the pressure has been dominant, and the pressure increases with the injection time.

For all temperatures, the growth rate of pressure increases over time, and at a certain point in time, the same time as the corresponding temperature of the rapid growth of viscosity, that is, the higher the temperature, the sooner the rapid growth and the faster the growth rate. Furthermore, the maximum pressure required for slurry cannot be determined simply by comparing temperatures; at high temperatures, the viscosity of the slurry is higher, but it is faster to seal the fissure; so, the maximum injection pressure required is lower. The maximum pressure at $60^{\circ} \mathrm{C}$ is the smallest of all temperatures simulated in this paper.

(2) Pressure Spatial Distribution. Monitor the distribution of pressure on line 1 and line 2, as shown in Figure 17. The spatial distribution law of C-S slurry in moving water is similar to that in static water, whether it is line 1 or line 2 , the pressure is decreasing after staying away from the injection hole, and the closer the injection hole, the faster the drop speed, in the range of $0.2 \mathrm{~m}$ that can decay by $80 \%$. Furthermore, the longer the slurry time, the higher the pressure at the same position, and the faster the pressure drops. On line 1, the 


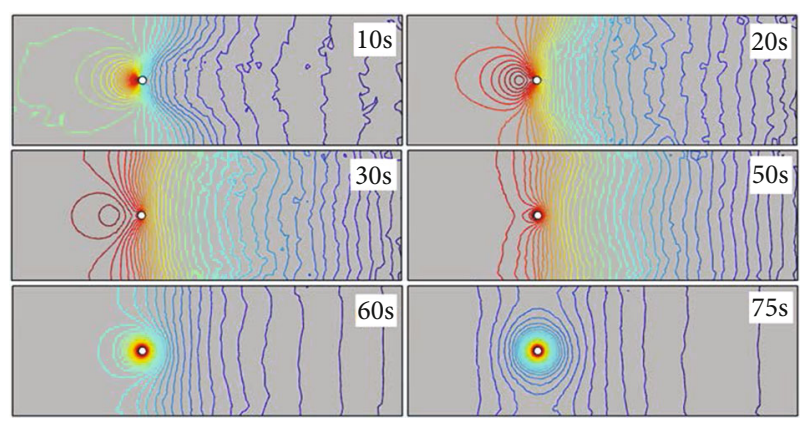

(a) $25^{\circ} \mathrm{C}$

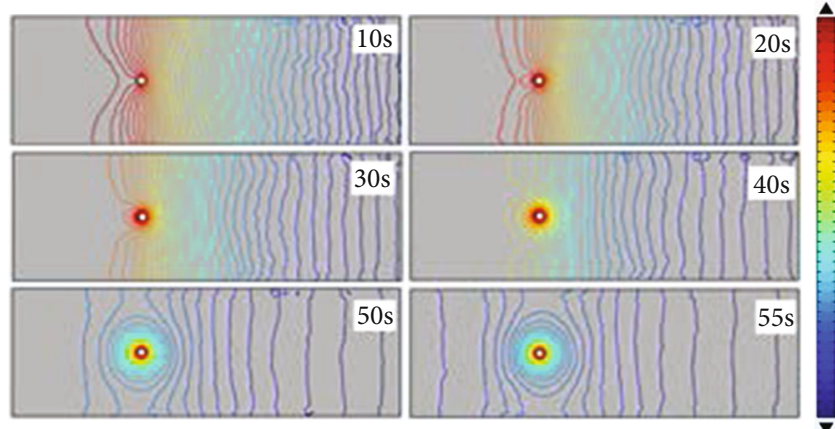

(c) $60^{\circ} \mathrm{C}$

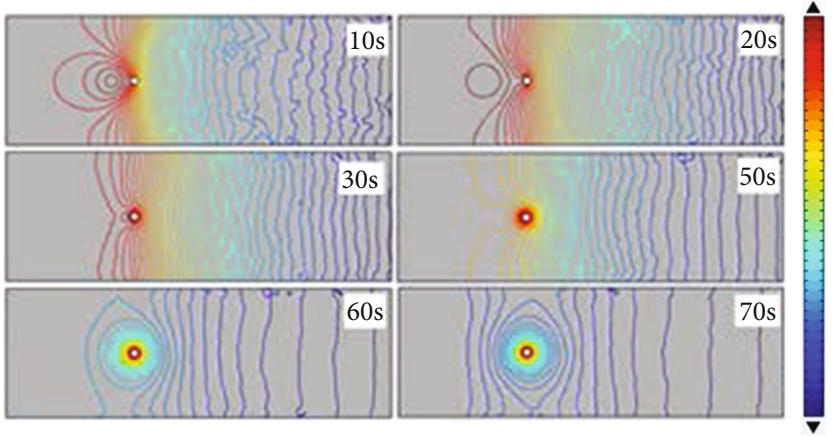

(b) $40^{\circ} \mathrm{C}$

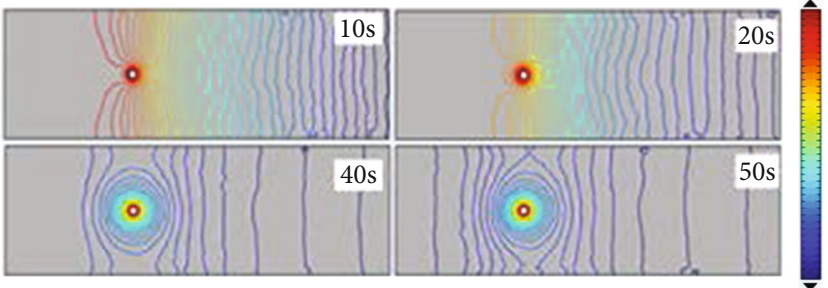

(d) $80^{\circ} \mathrm{C}$

FIGURE 15: C-S slurry pressure contour.

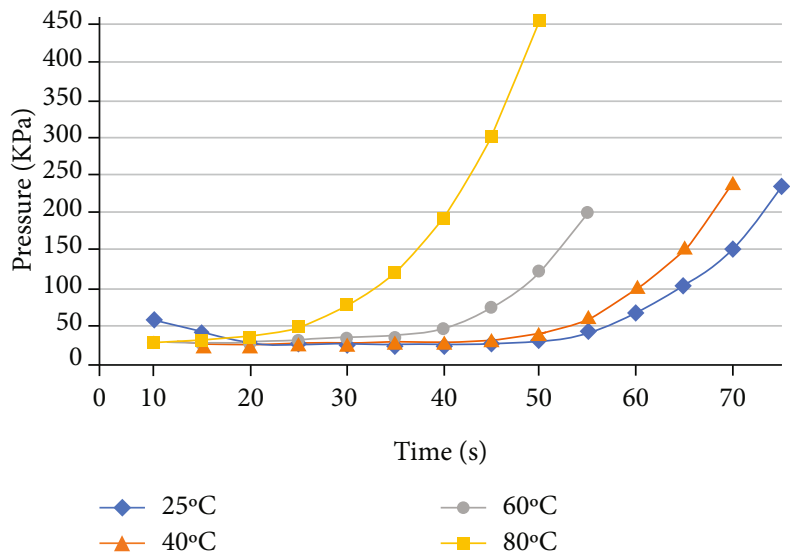

FIGURE 16: Grouting pressure varies with time of C-S slurry.

pressure on the right side of the injection slurry hole is lower than the pressure on the left side of the injection hole at the same distance due to the influence of the backwater side, and the pressure attenuation speed on the right side is faster; on line 2 , the same distance, the longer the slurry time, and the higher the temperature, the greater the pressure, and the faster the pressure drop.

\section{Discussion}

Previous researchers have carried out extensive grouting laboratory tests as well as theoretical and numerical experi- ments. To verify the accuracy of numerical simulation in this study, the room temperature part of simulation results was qualitatively compared with the study results of $\mathrm{Li}$ et al. [45].

$\mathrm{Li}$ et al. used C-S grout for the grouting test, the cement used in the test was P.O.32.5, and the volume ratio of W: $\mathrm{S}$ was $1: 1$. The grouting model is $4 \mathrm{~m}$ long and $2 \mathrm{~m}$ wide, the grouting hole diameter is $5 \mathrm{~mm}$, and the grouting speed of $\mathrm{Li}$ et al. is $0.4 \mathrm{~m} / \mathrm{s}$. [46] For a hydrostatic environment, the volume ratio of $\mathrm{C}: \mathrm{S}$ is $1: 1$. [47] For the flow environment, the flow velocity is $0.6 \mathrm{~m} / \mathrm{s}$. [48] The comparison of the results is shown in Figures 18 and 19. 


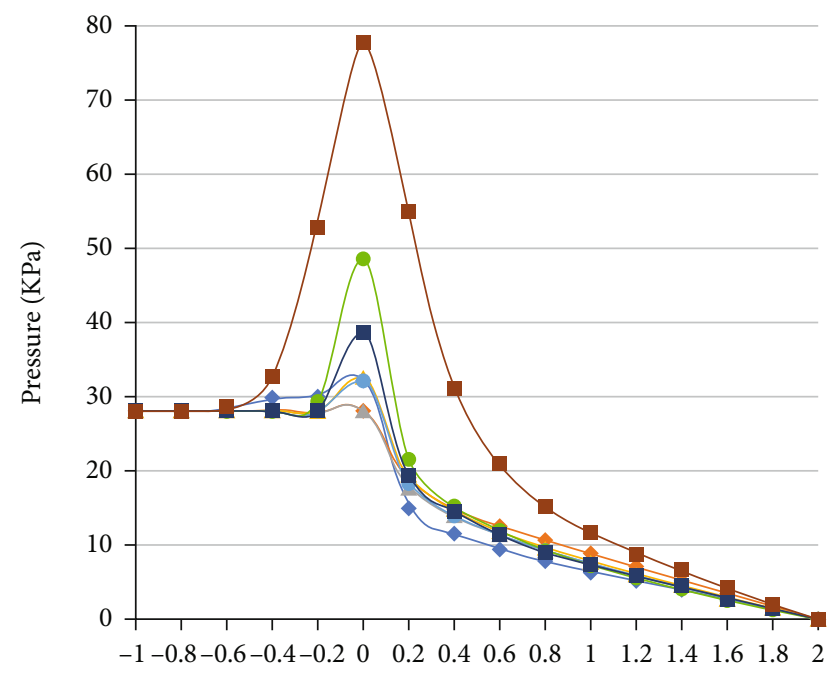

Distance from grouting hole (m)

\begin{tabular}{|c|c|}
\hline$\multimap \quad 25^{\circ} \mathrm{C}, 20 \mathrm{~s}$ & $-60^{\circ} \mathrm{C}, 20 \mathrm{~s}$ \\
\hline$\multimap \quad 25^{\circ} \mathrm{C}, 40 \mathrm{~s}$ & $\rightarrow 60^{\circ} \mathrm{C}, 40 \mathrm{~s}$ \\
\hline$\triangle \quad 40^{\circ} \mathrm{C}, 20 \mathrm{~s}$ & $-80^{\circ} \mathrm{C}, 20 \mathrm{~s}$ \\
\hline$\triangle \quad 40^{\circ} \mathrm{C}, 40 \mathrm{~s}$ & $80^{\circ} \mathrm{C}, 4$ \\
\hline
\end{tabular}

(a) Line1

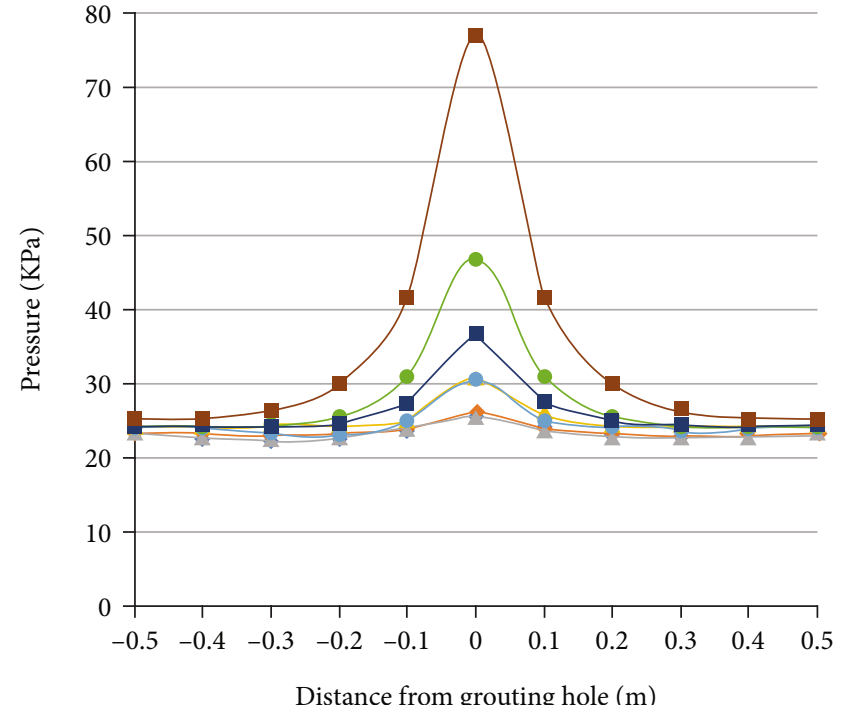

Distance from grouting hole (m)

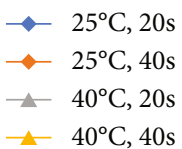

$-60^{\circ} \mathrm{C}, 20 \mathrm{~s}$

- $60^{\circ} \mathrm{C}, 40 \mathrm{~s}$

- $80^{\circ} \mathrm{C}, 20 \mathrm{~s}$

$-80^{\circ} \mathrm{C}, 30 \mathrm{~s}$

(b) Line2

FIgURE 17: Variation in the pressure space of C-S slurry.

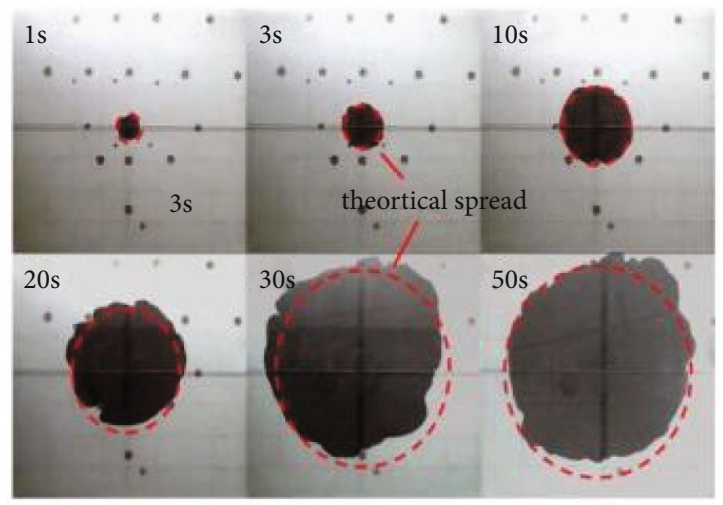

(a) Experimental results of Li et al.

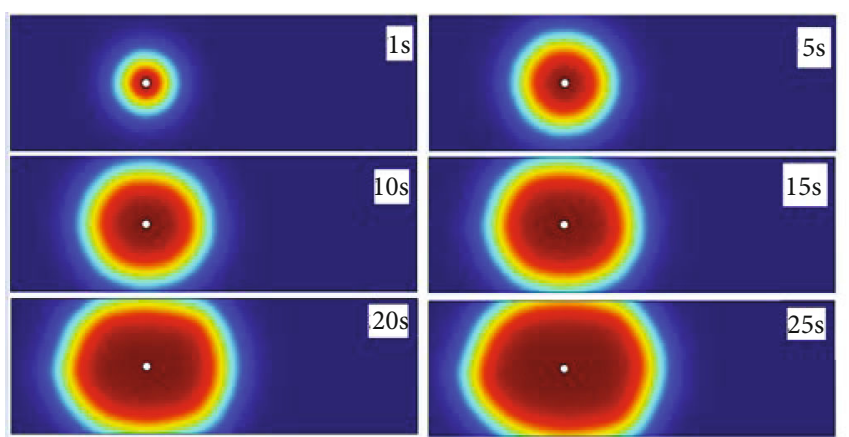

(b) Simulation results of C-S slurry

FIGURE 18: Comparison of results in hydrostatic environment. 


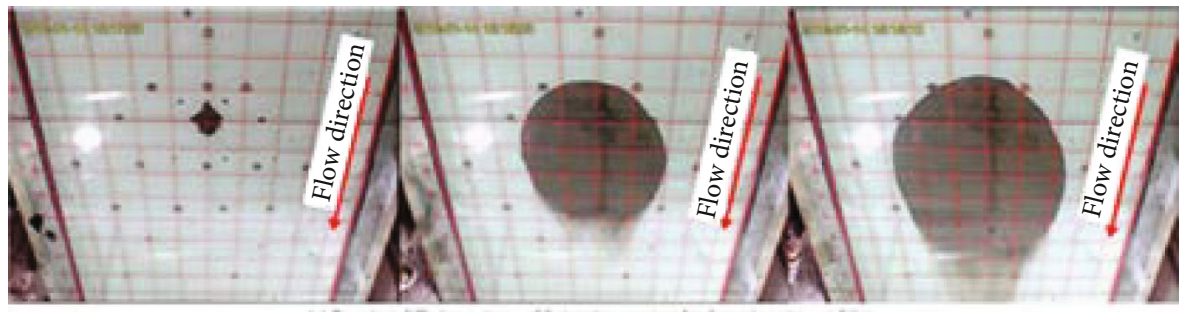

(a) Experimental results of Li et al.

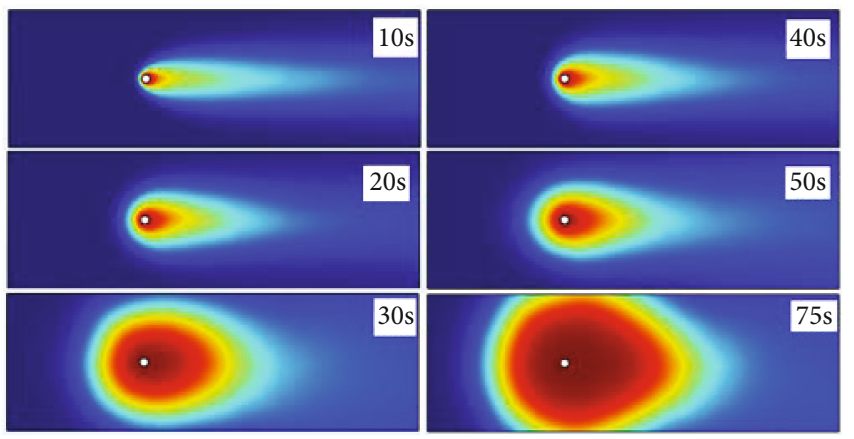

(b) Simulation results of C-S slurry

Figure 19: Comparison of results in a flow environment.

In the hydrostatic environment, the diffusion behavior of slurry is circular, and the simulation results are consistent with the experimental results. In the flow environment, the grout initially has an elliptical distribution, and then the diffusion form of the grout gradually changes from a closed elliptic shape to a U-shaped shape, with the diffusion range in the upstream direction being smaller than the diffusion range in the downstream direction. The simulation results agree well with the experimental results.

Based on the above analysis, the diffusion behavior of grout and grouting pressure change at room temperature is similar to the experimental law of other scholars. The results show that the established values are stable and feasible in fractured media and can be used to analyze fracture grouting at different temperatures.

\section{Conclusion}

Slurry injection is a commonly used engineering treatment, but the diffusion characteristic C-S of slurry will change in the high-temperature environment. A numerical simulation study on the diffusion law of high-temperature betting slurry was conducted based on the viscosity characteristic C-S of cement and water glass measured by indoor tests at different temperatures. From this study, we can draw the following conclusions.

(1) Under a hydrostatic environment, the diffusion rate of slurry is independent of the temperature and the type of slurry, the time required for the slurry to seal the fissure is the same, but the temperature change, and the slurry type will lead to a change in the injection pressure: the same slurry, the higher the tem- perature, and the higher the pressure required for slurry injection

(2) In the flow environment, C-S slurry blocking effect is better than the cement slurry blocking effect; at the same time, C-S slurry has been able to seal the cracks, and cement slurry viscosity is still not enough to resist the washing of water flow

(3) For cement slurry, the effect of temperature change on the diffusion pattern of slurry and the injection pressure is not obvious. The higher the temperature of the C-S slurry, the shorter the time required to seal, but the pressure rises faster, and the final sealing gap requires injection pressure to be reduced and then increased

\section{Data Availability}

The data used to support the findings of this study are available from the corresponding author upon request.

\section{Conflicts of Interest}

The authors declare that there is no conflict of interest regarding the publication of this paper.

\section{Authors' Contributions}

Jiandong Niu and Yong Sun contributed equally to this work.

\section{Acknowledgments}

The authors would like to thank the Natural Science Foundation of Hunan Province and the College Student 
Innovation and Entrepreneurship Training Program. This research is supported by the Natural Science Foundation of Hunan Province [2021JJ30832] and the College Student Innovation and Entrepreneurship Training Program [S2021105330618].

\section{References}

[1] H. Strømsvik, "The significance of hydraulic jacking for grout consumption during high pressure pre-grouting in Norwegian tunnelling," Tunnelling and Underground Space Technology, vol. 90, pp. 357-368, 2019.

[2] J. Niu, B. Wang, H. Wang et al., "An intelligent prediction method of the karst curtain grouting volume based on support vector machine," Geofluids, vol. 2020, Article ID 8892106, 14 pages, 2020.

[3] P. Q. Mo, H. H. Chen, and H. S. Yu, "Undrained cavity expansion in anisotropic soils with isotropic and frictional destructuration," Acta Geotechnica, pp. 1-22, 2021.

[4] P. Q. Mo, A. M. Marshall, and Y. Fang, "Cavity expansioncontraction-based method for tunnel-soil-pile interaction in a unified clay and sand model: drained analysis," International Journal of Geomechanics, vol. 21, no. 5, article 04021055, 2021.

[5] Y. G. Chen, Z. Sun, W. M. Ye, and Y. J. Cui, "Adsorptive removal of $\mathrm{Eu}(\mathrm{III})$ from simulated groundwater by GMZ bentonite on the repository conditions," Journal of Radioanalytical and Nuclear Chemistry, vol. 311, no. 3, pp. 1839-1847, 2017.

[6] H. Li, Y. Zhang, J. Wu, X. Zhang, L. Zhang, and Z. Li, "Grouting sealing mechanism of water gushing in karst pipelines and engineering application," Construction and Building Materials, vol. 254, article 119250, 2020.

[7] C. Zhang, J. Y. Fu, J. F. Yang, X. Ou, X. Ye, and Y. Zhang, "Formulation and performance of grouting materials for underwater shield tunnel construction in karst ground," Construction and Building Materials, vol. 187, pp. 327-338, 2018.

[8] Y. B. Lai, S. Li, J. Q. Guo, Z. G. Zhu, and X. Huang, "Analysis of seepage and displacement field evolutionary characteristics in water inrush disaster process of karst tunnel," Geofluids, vol. 2021, Article ID 5560762, 2020 pages, 2021.

[9] Y. G. Chen, X. M. Liu, H. N. Lei, W. M. Ye, and Y. J. Cui, "Adsorption property of $\mathrm{Pb}(\mathrm{II})$ by the laterite-bentonite mixture used as waste landfill liner," Advances in Civil Engineering, Article ID 2879156, 2011 pages, 2019.

[10] J. Niu, Y. Sun, B. Wang et al., "Grouting treatment of water and mud inrush in fully weathered granite tunnel: a case study," Geofluids, vol. 2020, Article ID 8838769, 18 pages, 2020.

[11] Y. Mei, X. Y. Zhang, X. Z. Nong, and L. Y. Fu, "Experimental study of the comprehensive technology of grouting and suspension under an operating railway in the cobble stratum," Transportation Geotechnics, vol. 30, article 100612, 2021.

[12] P. Q. Mo and H. S. Yu, "Undrained cavity-contraction analysis for prediction of soil behavior around tunnels," International Journal of Geomechanics, vol. 17, no. 5, article 04016121, 2017.

[13] Y. G. Chen, X. X. Dong, X. D. Zhang, W. M. Ye, and Y. J. Cui, "Oedometric compression and thermal volume behavior of compacted Gaomiaozi bentonite saturated with salt solution," Geomechanics for Energy and the Environment, vol. 25, article 100186, 2021.

[14] X. L. Gan, J. L. Yu, X. N. Gong, Y. Hou, N. Liu, and M. Zhu, "Response of operating metro tunnels to compensation grout- ing of an underlying large-diameter shield tunnel: A case study in Hangzhou," Underground Space, 2021.

[15] S. M. Wang, C. He, L. Nie, and G. C. Zhang, "Study on the long-term performance of cement-sodium silicate grout and its impact on segment lining structure in synchronous backfill grouting of shield tunnels," Tunnelling and Underground Space Technology, vol. 92, article 103015, 2019.

[16] P. Q. Mo, X. W. Gao, W. B. Yang, and H. S. Yu, "A cavity expansion-based solution for interpretation of CPTu data in soils under partially drained conditions," International Journal for Numerical and Analytical Methods in Geomechanics, vol. 44, no. 7, pp. 1053-1076, 2020.

[17] Y. G. Chen, Y. Q. Cai, K. Pan, W. M. Ye, and Q. Wang, "Influence of dry density and water salinity on the swelling pressure and hydraulic conductivity of compacted GMZ01 bentonitesand mixtures," Acta Geotechnica, pp. 1-18, 2021.

[18] X. Y. Ye, H. Moayedi, M. Khari, and L. K. Foong, "Metaheuristic-hybridized multilayer perceptron in slope stability analysis," Smart Structures and Systems, vol. 26, no. 3, pp. 263-275, 2020.

[19] W. Q. Mu, D. Y. Wang, L. C. Li et al., "Cement flow in interaction rock fractures and its corresponding new construction process in slope engineering," Construction and Building Materials, vol. 303, article 124533, 2021.

[20] J. D. Niu, Z. W. Li, W. H. Gu, and K. Chen, "Experimental study of split grouting reinforcement mechanism in filling medium and effect evaluation," Sensors, vol. 20, no. 11, article 3088, 2020.

[21] J. S. Yang, C. Zhang, J. Y. Fu, S. Wang, X. Ou, and Y. Xie, "Pregrouting reinforcement of underwater karst area for shield tunneling passing through Xiangjiang River in Changsha, China," Tunnelling and Underground Space Technology, vol. 100, article 103380, 2020.

[22] P. Q. Mo and H. S. Yu, "Drained cavity expansion analysis with a unified state parameter model for clay and sand," Canadian Geotechnical Journal, vol. 55, no. 7, pp. 1029-1040, 2018.

[23] X. Y. Ye, S. Y. Wang, Q. Li, S. Zhang, and D. C. Sheng, "Negative effect of installation on performance of a compaction-grouted soil nail in poorly graded Stockton beach sand," Journal of Geotechnical and Geoenvironmental Engineering, vol. 146, no. 8, article 04020061, 2020.

[24] X. Y. Ye, S. Y. Wang, S. Zhang, X. Xiao, and F. Xu, “The compaction effect on the performance of a compaction-grouted soil nail in sand," Acta Geotechnica, vol. 15, no. 10, pp. 2983-2995, 2020.

[25] X. Y. Ye, Q. Wang, S. Y. Wang, S. Sloan, and D. C. Sheng, "Performance of a compaction-grouted soil nail in laboratory tests," Acta Geotechnica, vol. 14, no. 4, pp. 1049-1063, 2019.

[26] X. Y. Ye, S. Y. Wang, Q. Wang, S. W. Sloan, and D. C. Sheng, "The influence of the degree of saturation on compactiongrouted soil nails in sand," Acta Geotechnica, vol. 14, no. 4, pp. 1101-1111, 2019.

[27] X. Y. Ye, S. Y. Wang, X. Xiao, S. Sloan, and D. C. Sheng, "Numerical study for compaction-grouted soil nails with multiple grout bulbs," International Journal of Geomechanics, vol. 19, no. 2, article 04018193, 2019.

[28] X. Y. Ye, Z. J. Lyu, and L. K. Foong, "Hybridized dragonfly, whale and ant lion algorithms in enlarged pile's behavior," Smart Structures and Systems, vol. 25, no. 6, pp. 765-778, 2020.

[29] Y. G. Chen, L. L. Guan, S. Y. Zhu, and W. J. Chen, "Foamed concrete containing fly ash: Properties and application to 
backfilling," Construction and Building Materials, vol. 273, article 121685, 2021.

[30] S. C. Li, D. D. Pan, Z. H. Xu, P. Lin, and Y. C. Zhang, "Numerical simulation of dynamic water grouting using quick-setting slurry in rock fracture: the Sequential Diffusion and Solidification (SDS) method," Computers and Geotechnics, vol. 122, article 103497, 2020.

[31] T. J. Shamu, L. Zou, and U. Håkansson, "A nomogram for cement-based rock grouting," Tunnelling and Underground Space Technology, vol. 116, article 104110, 2021.

[32] X. Yan, Z. Z. Sun, and Q. Q. Dong, “The unified pipe-interface element method for simulating the coupled hydro- mechanical grouting process in fractured rock with fracture propagation," Engineering Fracture Mechanics, vol. 256, article 107993, 2021.

[33] X. W. Liu, C. Hu, Q. S. Liu, and J. He, "Grout penetration process simulation and grouting parameters analysis in fractured rock mass using numerical manifold method," Engineering Analysis with Boundary Elements, vol. 123, pp. 93-106, 2021.

[34] X. W. Liu, H. X. Chen, Q. S. Liu, B. Liu, and J. He, "Modelling slurry flowing and analyzing grouting efficiency under hydromechanical coupling using numerical manifold method," Engineering Analysis with Boundary Elements, vol. 134, pp. 66-78, 2022.

[35] Z. Li, H. X. Liu, Z. L. Dun, L. W. Ren, and J. J. Fang, "Grouting effect on rock fracture using shear and seepage assessment," Construction and Building Materials, vol. 242, article 118131, 2020.

[36] J. Rafi and H. Stille, "A method for determining grouting pressure and stop criteria to control grout spread distance and fracture dilation," Tunnelling and Underground Space Technology, vol. 112, article 103885, 2021.

[37] Q. S. Zhang, L. Z. Zhang, R. T. Liu, S. C. Li, and Q. Q. Zhang, "Grouting mechanism of quick setting slurry in rock fissure with consideration of viscosity variation with space," Tunnelling and Underground Space Technology, vol. 70, pp. 262273, 2017.

[38] F. Xiao, J. L. Shang, and Z. Y. Zhao, "DDA based grouting prediction and linkage between fracture aperture distribution and grouting characteristics," Computers and Geotechnics, vol. 112, pp. 350-369, 2019.

[39] X. M. Du, H. Y. Fang, S. Y. Wang, B. H. Xue, and F. M. Wang, "Experimental and practical investigation of the sealing efficiency of cement grouting in tortuous fractures with flowing water," Tunnelling and Underground Space Technology, vol. 108, article 103693, 2021.

[40] J. D. Niu, B. Wang, C. Feng, and K. Chen, "Experimental research on viscosity characteristics of grouting slurry in a high ground temperature environment," Materials, vol. 13, no. 14, article 3221, 2020.

[41] Z. Xu, C. Liu, X. Zhou, G. Gao, and X. Feng, "Full-scale physical modelling of fissure grouting in deep underground rocks," Tunnelling and Underground Space Technology, vol. 89, pp. 249-261, 2019.

[42] X. Y. Xu, Z. J. Wu, H. Sun, L. Weng, Z. Chu, and Q. Liu, “An extended numerical manifold method for simulation of grouting reinforcement in deep rock tunnels," Tunnelling and Underground Space Technology, vol. 115, article 104020, 2021.

[43] Q. S. Liu and L. Sun, "Simulation of coupled hydro-mechanical interactions during grouting process in fractured media based on the combined finite-discrete element method," Tunnelling and Underground Space Technology, vol. 84, pp. 472-486, 2019.

[44] F. Sha, S. C. Li, R. T. Liu, Q. S. Zhang, and Z. F. Li, "Performance of typical cement suspension-sodium silicate double slurry grout," Construction and Building Materials, vol. 200, pp. 408-419, 2019.

[45] S. C. Li, R. T. Liu, Q. S. Zhang, and X. Zhang, "Protection against water or mud inrush in tunnels by grouting: a review," Journal of Rock Mechanics and Geotechnical Engineering, vol. 8, no. 5, pp. 753-766, 2016.

[46] Y. X. Guo, Q. S. Zhang, F. Xiao, R. T. Liu, Z. J Wang, and Y. K. Liu, "Grouting rock fractures under condition of flowing water," Carbonates and Evaporites, vol. 35, no. 3, Article ID 96, 2020.

[47] Q. S. Zhang, L. Z. Zhang, R. T. Liu et al., "Laboratory experimental study of cement-silicate slurry diffusion law of crack grouting with dynamic water," Rock Soil Mech, vol. 36, no. 8, pp. 59-68, 2015.

[48] L. Z. Zhang, Q. S. Zhang, R. T. Liu et al., "Penetration grouting mechanism of quick setting slurry considering spatiotemporal variation of viscosity," Rock Soil Mech, vol. 38, no. 2, pp. 443452, 2017. 